\title{
Gleason grading and prognostic factors in carcinoma of the prostate
}

\author{
Peter A Humphrey \\ Department of Pathology and Immunology, Washington University School of Medicine, Saint Louis, MO, USA
}

\begin{abstract}
Gleason grade of adenocarcinoma of the prostate is an established prognostic indicator that has stood the test of time. The Gleason grading method was devised in the 1960s and 1970s by Dr Donald F Gleason and members of the Veterans Administration Cooperative Urological Research Group. This grading system is based entirely on the histologic pattern of arrangement of carcinoma cells in H\&E-stained sections. Five basic grade patterns are used to generate a histologic score, which can range from 2 to 10 . These patterns are illustrated in a standard drawing that can be employed as a guide for recognition of the specific Gleason grades. Increasing Gleason grade is directly related to a number of histopathologic end points, including tumor size, margin status, and pathologic stage. Indeed, models have been developed that allow for pretreatment prediction of pathologic stage based upon needle biopsy Gleason grade, total serum prostate-specific antigen level, and clinical stage. Gleason grade has been linked to a number of clinical end points, including clinical stage, progression to metastatic disease, and survival. Gleason grade is often incorporated into nomograms used to predict response to a specific therapy, such as radiotherapy or surgery. Needle biopsy Gleason grade is routinely used to plan patient management and is also often one of the criteria for eligibility for clinical trials testing new therapies. Gleason grade should be routinely reported for adenocarcinoma of the prostate in all types of tissue samples. Experimental approaches that could be of importance in the future include determination of percentage of high-grade Gleason pattern 4 or 5 , and utilization of markers discovered by gene expression profiling or by genetic testing for DNA abnormalities. Such markers would be of prognostic usefulness if they provided added value beyond the established indicators of Gleason grade, serum prostatespecific antigen, and stage. Currently, established prognostic factors for prostatic carcinoma recommended for routine reporting are TNM stage, surgical margin status, serum prostate-specific antigen, and Gleason grade. Modern Pathology (2004) 17, 292-306, advance online publication, 13 February 2004; doi:10.1038/modpathol.3800054
\end{abstract}

Keywords: prostate; cancer; Gleason grade; prognosis

\section{Grading of prostatic carcinoma}

Grade may be as defined as a step in a process. ${ }^{1}$ Histological grade of a neoplastic process is often equated with the degree of differentiation of the neoplastic cells. Since the time of Virchow, it has been recognized that the grade of a neoplasm is related to its malignant potential. ${ }^{2}$ It was not until 1920, however, that Broders, in his seminal study of 537 squamous cell carcinomas of the lip, devised a scheme that stratified malignant neoplasms based upon the degree of differentiation. ${ }^{3}$

In the last three-quarters of the 20th century, over 40 histologic grading systems for prostatic carcinoma have been proposed (reviewed in Humphrey ${ }^{4}$ ). These systems have typically utilized differentiation capacity, architectural growth patterns, mitotic

Correspondence: PA Humphrey, Department of Pathology and Immunology, Box 8118, Washington University Medical Center, 660 South Euclid Avenue, St Louis, MO 63110, USA.

E-mail: humphrey@path.wustl.edu

Received and accepted 9 July 2003; published online 13 February 2004 activity, and nuclear abnormalities in generation of a histological grade assignment.

Currently, the most widely used grading scheme in the US and worldwide is the Gleason system, ${ }^{5-10}$ while other grading methods, such as the World Health Organization (WHO) system, ${ }^{11,12}$ are applied in some laboratories. Both of these grading methods are based on standard light microscopic interpretation of H\&E-stained tissue sections. The Gleason grading system is based entirely on architectural growth patterns of prostatic carcinoma, while the WHO scheme incorporates both gland-forming ability and nuclear anaplasia.

\section{Gleason system}

General Approach

The Gleason grading system for prostatic carcinoma is the dominant method around the world in research and in daily practice. This technique was developed by Dr Donald F Gleason, a pathologist in Minnesota, and members of the Veterans Adminis- 
tration Cooperative Urological Research Group (VACURG). ${ }^{5-10}$ From 1960 to 1975 the VACURG enrolled roughly 5000 prostate cancer patients in prospective randomized clinical trials. One of the outstanding strengths of the Gleason grading system is that it was tested in this large patient population, with long-term follow-up that included use of survival as an end point.

The Gleason grading system is based entirely on the histologic pattern of arrangement of carcinoma cells in H\&E-stained prostatic tissue sections. Specifically, the method is one of categorization of histologic patterns 'at relatively low magnification ( $\times 10-40)$ by the extent of glandular differentiation and the pattern of growth of the tumor in the prostatic stroma'. ${ }^{10}$ Nine growth patterns were consolidated into five grades and these were illustrated in a drawing by Dr Gleason (Figure 1).

The five basic grade patterns are used to generate a histologic score, which can range from 2 to 10, by adding the primary grade pattern and the secondary grade pattern. The primary pattern is the one that is predominant in area, by simple visual inspection. The secondary pattern is the second most common pattern. If only one grade is in the tissue sample, that grade is multiplied by two to give the score. According to the Gleason approach of 1977, if the

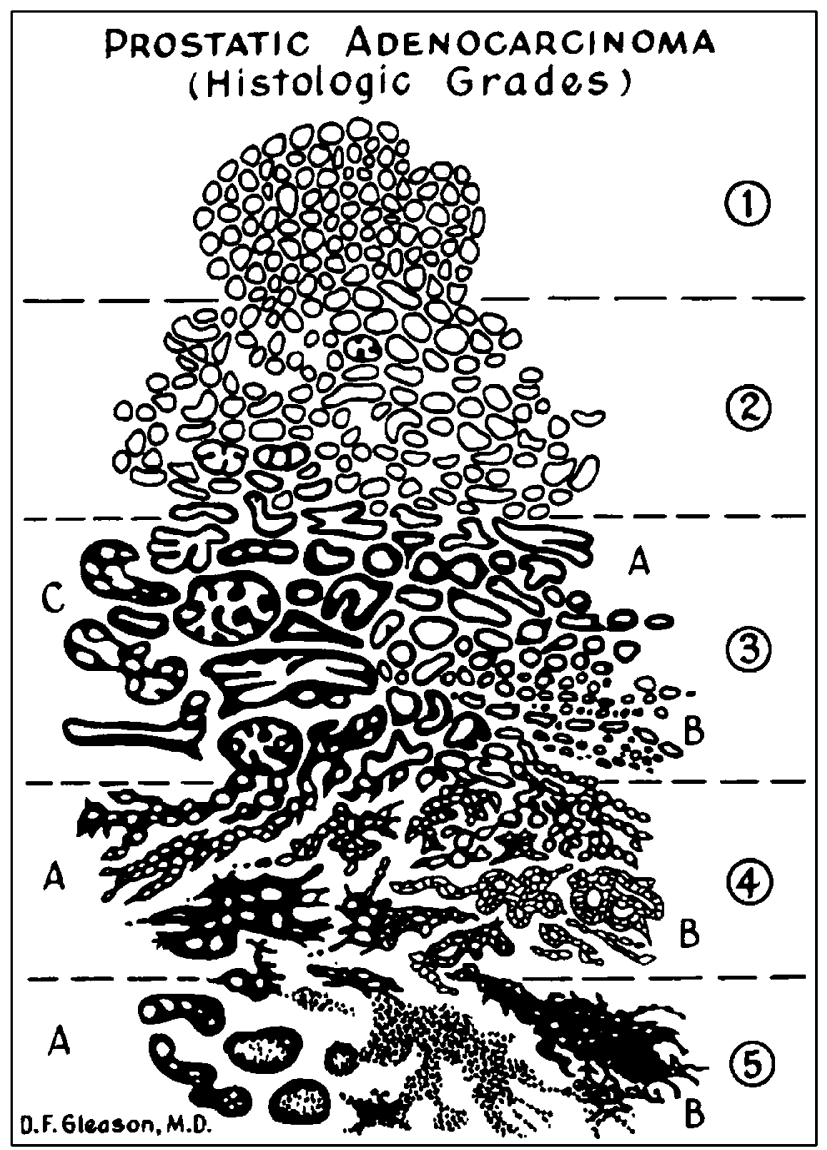

Figure 1 Gleason grades: standard drawing. second grade is less than $3 \%$ of the total tumor, it is ignored, and the primary grade is again doubled to give the Gleason score. ${ }^{8}$ Gleason sum, Gleason grade, combined Gleason grade, and category score have been used as synonyms for Gleason score, but 'histological pattern score' was the initial 1974 designation for the sum of the two patterns ${ }^{6}$ and 'histologic score' has endured in usage in the writings of Gleason. ${ }^{7-10}$

The assignment of a Gleason score, which is the addition of the two most common patterns, essentially averages the primary and secondary grades. This procedure appears to be unique in grading of human cancers, where, for other malignancies, it is the worst grade that determines patient outcome. Peculiarly, for prostatic carcinoma, when there are two different Gleason grade patterns, the cancer death rates are intermediate between the rates for patients with only the pure form of each of those two grades. ${ }^{8-10}$

The Gleason grading system allows for two separate grade patterns in an individual tissue sample, but the histomorphological appearance of prostatic carcinoma is more heterogeneous than this. Indeed, in one study, ${ }^{13}$ an average of 2.7 Gleason grade patterns (range 1-5) was found in carcinomas in whole prostate glands. Two additional papers reported that $14-18 \%$ of patients had more than two grades in sections of their prostatic carcinoma. ${ }^{14,15}$ In one of these reports, ${ }^{15} 3 \%$ of cases had four different Gleason patterns. The number of grades assigned depends on tumor sample size and size of the tumor in the whole gland. So, more than two grades is more often observed in TURP chips (28\% of cases) compared to needle biopsies (4\% of cases), ${ }^{14}$ and tumors greater than $1-2 \mathrm{~cm}^{3}$ in size tended to have more than two grades. ${ }^{13,15}$

There are limited data on how to grade carcinomas with more than two grades. Gleason wrote that the VACURG was unable to acquire enough threegrade tumors to evaluate their behavior, ${ }^{10}$ and proposed an algorithm to provide a Gleason score in cases with more than two grades. ${ }^{10}$ Recent data on radical prostatectomy specimens indicate that a high-grade Gleason pattern 4 or 5 that is a tertiary component occupying less than $5 \%$ of the tumor influences pathological stage and progression rates. ${ }^{16}$ Therefore, any tertiary high-grade pattern should be mentioned in surgical pathology reports. In needle biopsies, Gleason has recommended that the two highest grades be recorded. ${ }^{10}$ Another recommendation for needle biopsy cases in which more than two patterns are present and the worst grade is neither the predominant nor the secondary grade, the predominant and the highest grade should be chosen to arrive at a score. ${ }^{17}$ More data and analyses are needed to establish a definitive approach to scoring when more than two patterns are present.

'Lumping' or 'grade compression' by combining Gleason scores in attempts to translate to other grading systems should be avoided. Such grouping 
often results in loss of information, with the risk of combining grades of different biologic aggressiveness into one larger category. Many different approaches to lumping of Gleason scores have been published. As compared to the nine groups of Gleason score 2-10, groupings of two, three, and four categories have been utilized. A common practice has been to translate Gleason score 2-4 carcinoma as well-differentiated, Gleason score 5-7 as moderately differentiated, and Gleason score 810 as poorly differentiated. Yet, Gleason score 7 carcinoma harbors an element of high-grade pattern carcinoma, and is intermediate in clinical aggressiveness between patterns $5-6$ and $8-10,{ }^{18-20}$ and should not be included in a moderately differentiated category. If lumping is necessary due to low patient numbers in a research setting, the $2-6$ vs 7 vs 8-10 lump or 2-4 vs 5-6 vs 7 vs 8-10 lump seems most appropriate.

\section{Gleason Pattern 1 (Grade 1)}

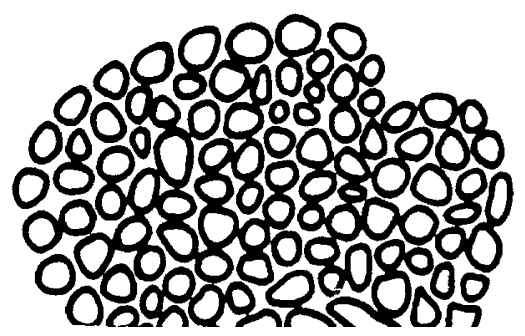

This is a rare pattern of very well-differentiated growth of closely packed but separate, uniform, rounded to oval, medium-sized acini (Table 1). Of the original 2911 cases of prostatic carcinoma in the VACURG series, this pattern was found in $3.5 \%$ of cases. ${ }^{8}$ Of critical importance, this is a nodular and circumscribed mass of glands with a rounded border of tumoral-stromal interface. Infiltration of malignant acini into surrounding stroma, including encirclement of benign glands, or penetration between benign glands, is indicative of a higher grade carcinoma. Also, the back-to-back glands should be separated by thin stromal rims. If tumor cells form back-to-back glands, without intervening stroma, then the Gleason pattern is high-grade 4, not pattern 1 or 2 . Pattern 1 is most often admixed with pattern 2 to yield a Gleason score of $3^{8}$ (Figure 2). A pure pattern 1 adenocarcinoma, with Gleason grade $1+1=$ score of 2 is rare to nonexistent. In the VACURG series, score 2 adenocarcinomas comprised less than $1 \%$ of all cases. This author has never diagnosed a pure pattern 1 . Combinations of pattern 1 with intermediate-grade Gleason pattern 3 and high-grade Gleason patterns 4 and 5 are vanishingly rare. Before diagnosing a pure Gleason pattern 1 adenocarcinoma, one should exclude atypical adenomatous hyperplasia (adenosis).

Pattern 1 carcinoma is most often an incidental finding in transition zone tissue, diagnosed in TURP chips resected due to a clinical diagnosis of BPH or in radical prostatectomies performed due to detec-

Table 1 Gleason grading system for prostatic adenocarcinoma

\begin{tabular}{|c|c|c|c|c|}
\hline Pattern & Tumor shape and borders & Stromal invasion & Tumor cell arrangements & Gland size \\
\hline 1 & $\begin{array}{l}\text { Nodular, well-defined and } \\
\text { smooth edges }\end{array}$ & Pushing & $\begin{array}{l}\text { Single, round to oval, closely } \\
\text { packed, but separate glands }\end{array}$ & Medium \\
\hline 2 & $\begin{array}{l}\text { Masses less well-defined and } \\
\text { less well-circumscribed }\end{array}$ & $\begin{array}{l}\text { Some gland separation } \\
\text { at tumor edge }\end{array}$ & $\begin{array}{l}\text { Single, separate, round to oval } \\
\text { glands, with more variation in } \\
\text { gland size and shape, and } \\
\text { loosely packed with stromal } \\
\text { separation (up to one gland } \\
\text { diameter, on average) }\end{array}$ & Medium \\
\hline $3 \mathrm{~A}$ & Ill-defined infiltrating edges & Irregular extension & $\begin{array}{l}\text { Single separate glands of } \\
\text { variable shape and size, with } \\
\text { elongated, angular and twisted } \\
\text { forms, usually with wide } \\
\text { stromal separation }\end{array}$ & Medium \\
\hline $3 \mathrm{~B}$ & Ill-defined infiltrating edges & Irregular extension & $\begin{array}{l}\text { Same as } 3 \mathrm{~A} \text { but glands are } \\
\text { smaller }\end{array}$ & Small to very small \\
\hline $3 \mathrm{C}$ & $\begin{array}{l}\text { Masses and cylinders with } \\
\text { smooth rounded edges }\end{array}$ & Expansile & $\begin{array}{l}\text { Papillary and cribriform } \\
\text { epithelium, without necrosis }\end{array}$ & Medium to large \\
\hline $4 \mathrm{~A}$ & Raggedly infiltrative & Diffusely permeative & $\begin{array}{l}\text { Fused glands, creating masses, } \\
\text { cords, or chains }\end{array}$ & $\begin{array}{l}\text { Small, medium, or } \\
\text { large }\end{array}$ \\
\hline $4 \mathrm{~B}$ & Raggedly infiltrative & Diffusely permeative & $\begin{array}{l}\text { Similar to } 4 \mathrm{~A} \text {, but cells have } \\
\text { cleared } \\
\text { cytoplasm = hypernephromatoid } \\
\text { variant }\end{array}$ & $\begin{array}{l}\text { Small, medium, or } \\
\text { large }\end{array}$ \\
\hline $5 \mathrm{~A}$ & Smooth, rounded cylinders & Expansile & $\begin{array}{l}\text { Papillary, cribriform or solid } \\
\text { masses with central } \\
\text { necrosis = comedocarcinoma }\end{array}$ & Variable \\
\hline $5 B$ & Raggedly infiltrative & Diffusely permeative & $\begin{array}{l}\text { Masses and sheets of anaplastic } \\
\text { carcinoma, with a few tiny } \\
\text { glands or signet ring cells }\end{array}$ & Small \\
\hline
\end{tabular}




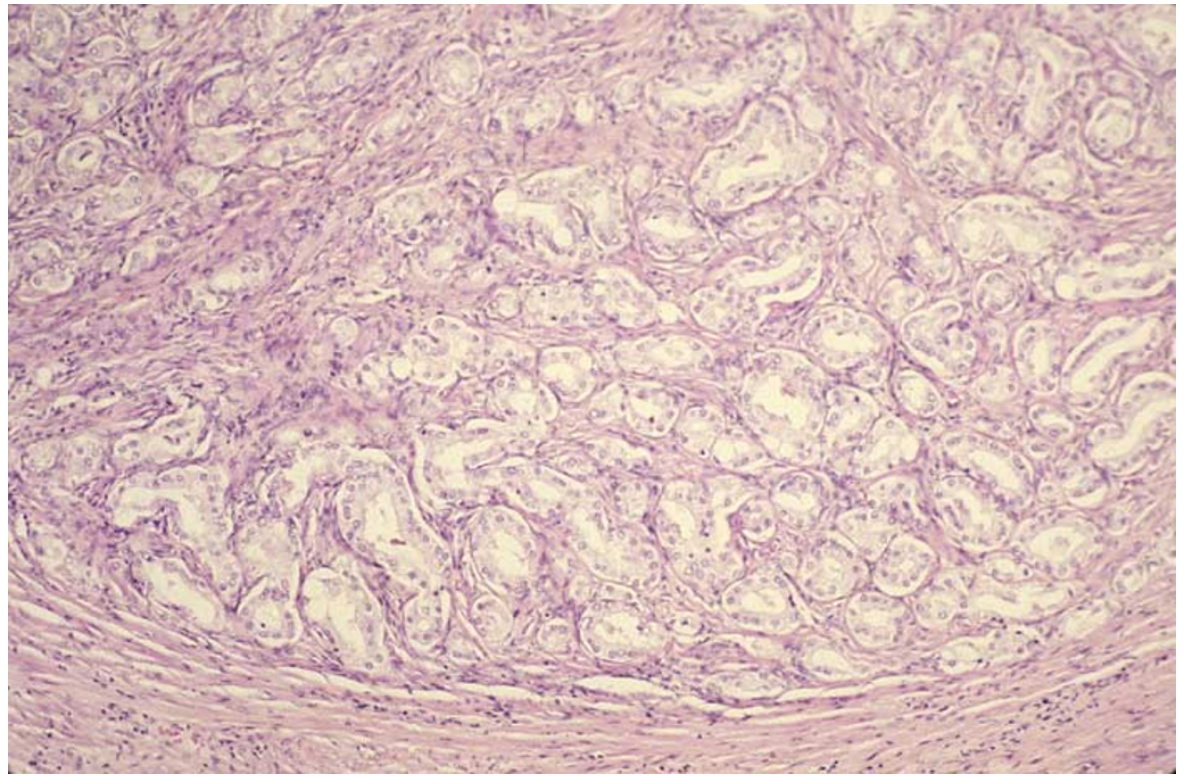

Figure 2 Gleason grade $2+1=$ score of three adenocarcinoma.

tion of an associated, peripheral zone, intermediate to high-grade carcinoma. It has been argued that well-differentiated Gleason pattern 1 and 2 adenocarcinomas should not be diagnosed in peripheral zone needle biopsies, since a diagnosis of Gleason score 2-4 carcinoma in needle biopsy almost always represents undergraded intermediate-grade carcinoma. ${ }^{21}$

Pattern scores are strongly correlated with tumor extent, expressed as the percent area of prostate tissue in TURP chips or radical prostatectomy specimens. ${ }^{8,22}$ So, pattern 1 in scores of 2 and 3 is usually a focal finding, involving less than $5-10 \%$ of prostatic tissue. ${ }^{8,22}$

\section{Gleason Pattern 2 (Grade 2)}

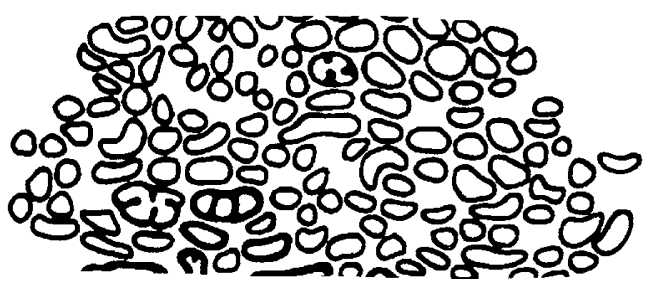

This well-differentiated pattern forms less welldefined masses that are not as circumscribed as pattern 1, with a tumor-stromal boundary that is not as rounded as pattern 1 . Compared to pattern 1 , the carcinomatous glands of pattern 2 display a degree of separation by stroma with an average separation distance of less than one gland diameter. Another distinctive characteristic of pattern 2 adenocarcino$m a$ is the increase in variability in gland size and shape. There is, however, only a limited capacity to infiltrate into stroma, as suggested by some gland separation at the periphery of the tumor mass. The original description of pattern $2^{5}$ and the standardized drawing of pattern 2 indicate that focal cribriform structures might be present, but cribriform arrangements are most characteristic of intermediate- to high-grade disease.

Pattern 2 is usually found admixed with pattern 3 to yield a Gleason score of $5 .^{8}$ In a small percentage of cases pattern 2 is pure (such that the score is $2+2=4$ ) (Figure 3 ), or is intermingled with pattern 1. A composite of pattern 2 with high-grade patterns 4 or 5 is extremely uncommon.

Pattern 2 adenocarcinoma, like pattern 1, is often an incidental finding in transition zone carcinomas and is thereby typically seen in TURP chips. Pattern 2 as a component of Gleason score 5 can also be found fairly commonly in radical prostatectomy specimens. In needle biopsy, one should diagnose pattern 2 in a Gleason score of 3 or 4 either rarely or not at all. ${ }^{21}$

Pattern 2 in the score setting of $4-5$ is often focal (less than $10 \%$ of tissue $^{22}$ ) but can be extensive, involving over $20-50 \%$ of TURP chip or prostatectomy tissue. ${ }^{8}$

\section{Gleason Pattern 3 (Grade 3)}

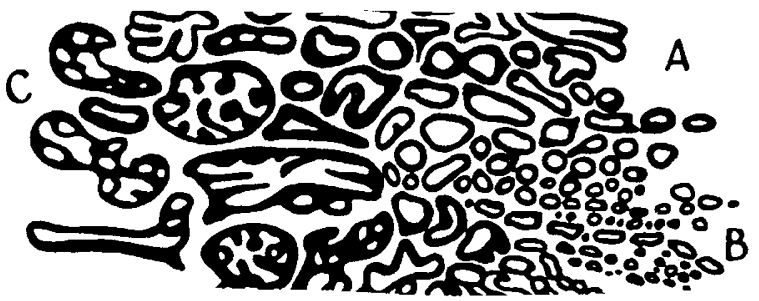

This moderately differentiated grade is the most common pattern of growth of prostatic adenocarcinoma, both in the pre-PSA $\mathrm{era}^{8}$ and in the PSA 


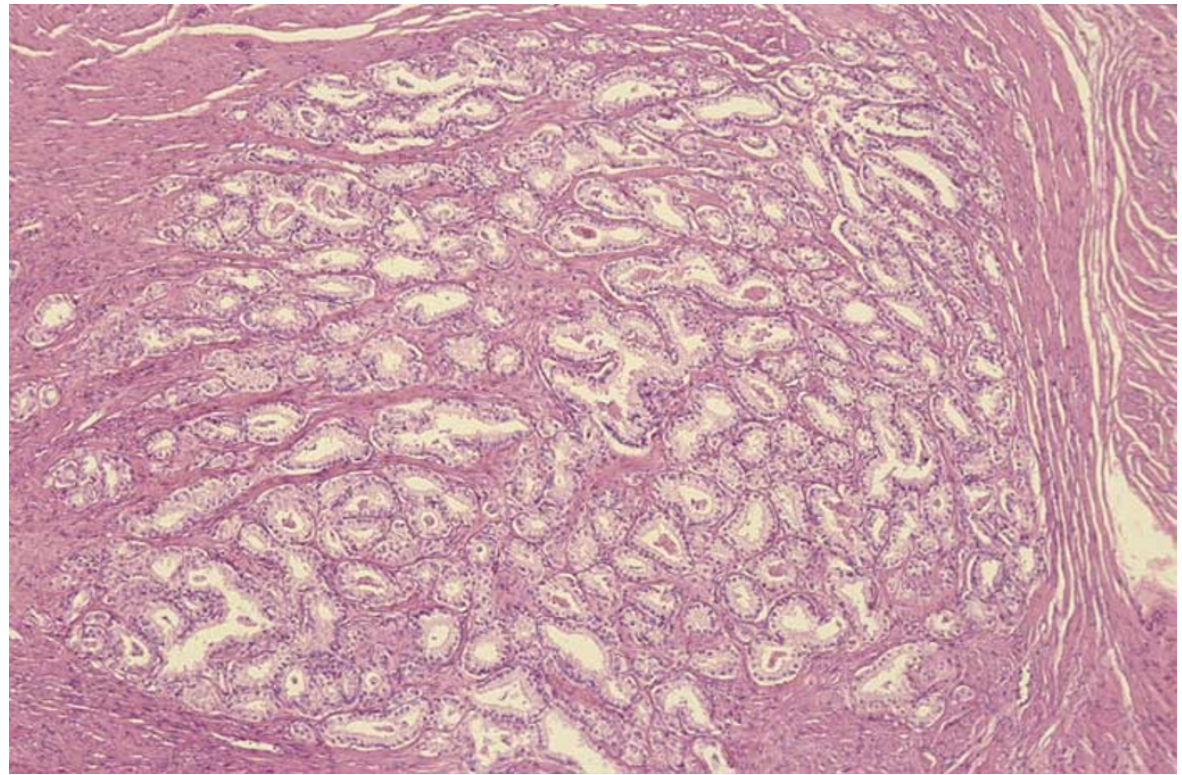

Figure 3 Gleason grade $2+2=$ score of 4 adenocarcinoma.

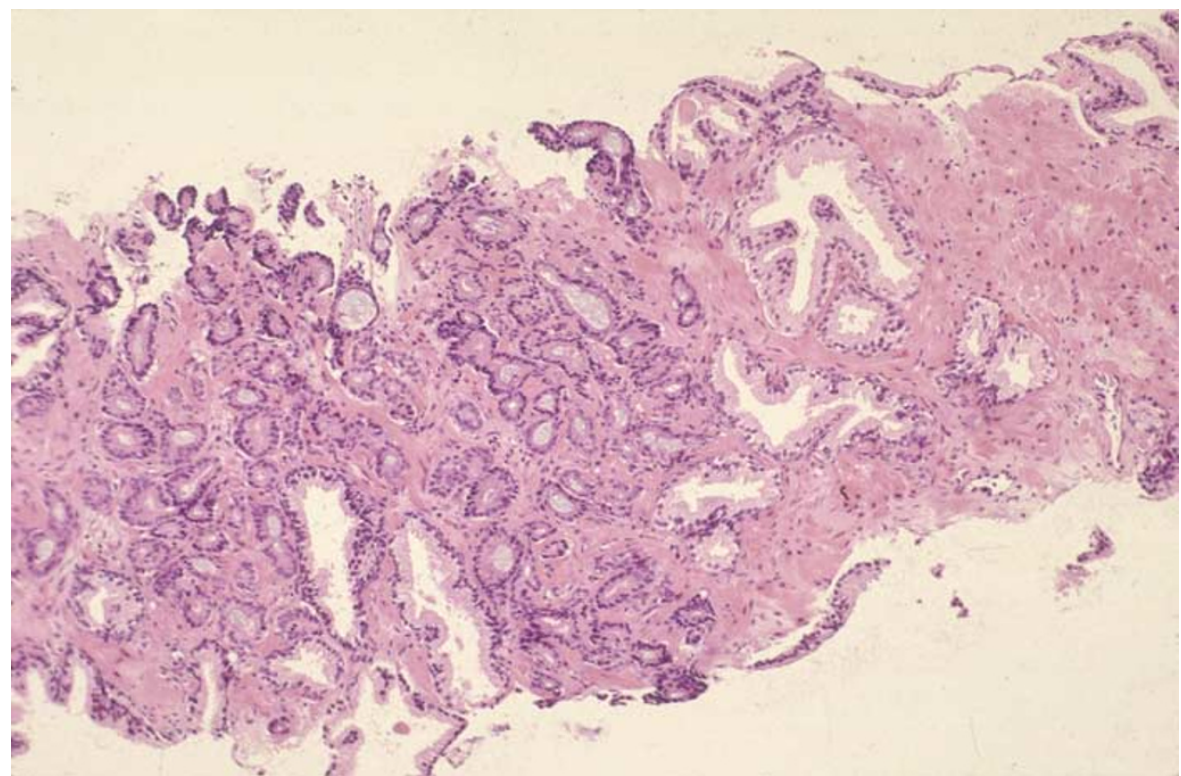

Figure 4 Gleason grade $3+3=$ score of 6 adenocarcinoma.

screening era. ${ }^{23}$ Pattern 3 has been characterized as having three distinctive appearances, designated patterns $3 \mathrm{~A}, 3 \mathrm{~B}$, and $3 \mathrm{C}$. It has been suggested that there is increased aggressiveness of pattern 3 carcinoma proceeding from pattern $3 \mathrm{~A}$ to $3 \mathrm{~B}$ to $3 \mathrm{C},{ }^{10}$ but no data have been published in support of this notion. Accordingly, it is not necessary to specify pattern 3A vs 3B vs 3C. Rather, these different subpatterns within the range of pattern images serve a role in recognition of grade 3 disease.

Gleason grade pattern 3A is characterized by infiltrating, medium-sized, single glands of irregular shape and spacing and haphazard, irregular extension of glands into stroma (Figure 4). There is typically appreciable stromal separation of glands, where the intervening stroma is usually greater than one gland diameter. Densely packed gland arrangements are allowable in pattern 3 , but there should be attendant evidence of infiltrative growth. The shape of the glands is quite variable, with angular, elongated, and 'twisted' forms described. ${ }^{10}$ The angular glands can have sharp corners or points. ${ }^{10}$ Pattern 3 adenocarcinoma glands are generally darker than well-differentiated patterns 1 and 2, which is due in part to cytoplasmic basophilia, ${ }^{10}$ but cytoplasmic features should not be used in Gleason grading; it is possible to detect Gleason pattern 3 glands with cytoplasmic clearing. 
Pattern 3B is essentially the same as $3 \mathrm{~A}$ except that the glands are smaller. These glands should still have the capability of forming glandular luminal spaces. If cords or chains without glandular lumina are seen, this is indicative of high-grade Gleason pattern 4, not intermediate-grade pattern 3.

Pattern 3C is comprised of expanded cylinders or ducts with masses of cribriform or papillary tumor. $^{9,10}$ Consistent with the possibility that this pattern actually represents intraductal growth, the tumor masses should have smooth, rounded edges, like expanded duct profiles. The Gleason grading scheme does not, however, distinguish in situ growth and invasive carcinoma, such that it is possible that some of these $3 \mathrm{C}$ patterns may be ducts with basal cells present. As such, some pattern 3C cribriform proliferations then represent cribriform high-grade prostatic intraepithelial neoplasia. ${ }^{24}$ Another view ${ }^{25}$ is that these duct lumen-spanning cribriform masses are intraductal carcinoma (carcinoma in situ), but this is not currently an accepted diagnostic entity. The papillary pattern 3C carcinomas, may, in similar fashion, represent in situ spread of the ductal variant of prostatic carcinoma. Cribriform masses can also present in high-grade Gleason pattern 4, but the edges of these masses are ragged and infiltrative, not smooth. Necrosis should not be seen in pattern $3 \mathrm{C}$; if necrosis is visible, pattern 5 , not pattern 3 , should be diagnosed.

Gleason grade pattern 3 is, in the large majority of cases, found in pure form, such that the most common Gleason score is $3+3=6$. It is also fairly common to identify Gleason pattern 3 in combination with low-grade pattern 2 for a score of 5 or in

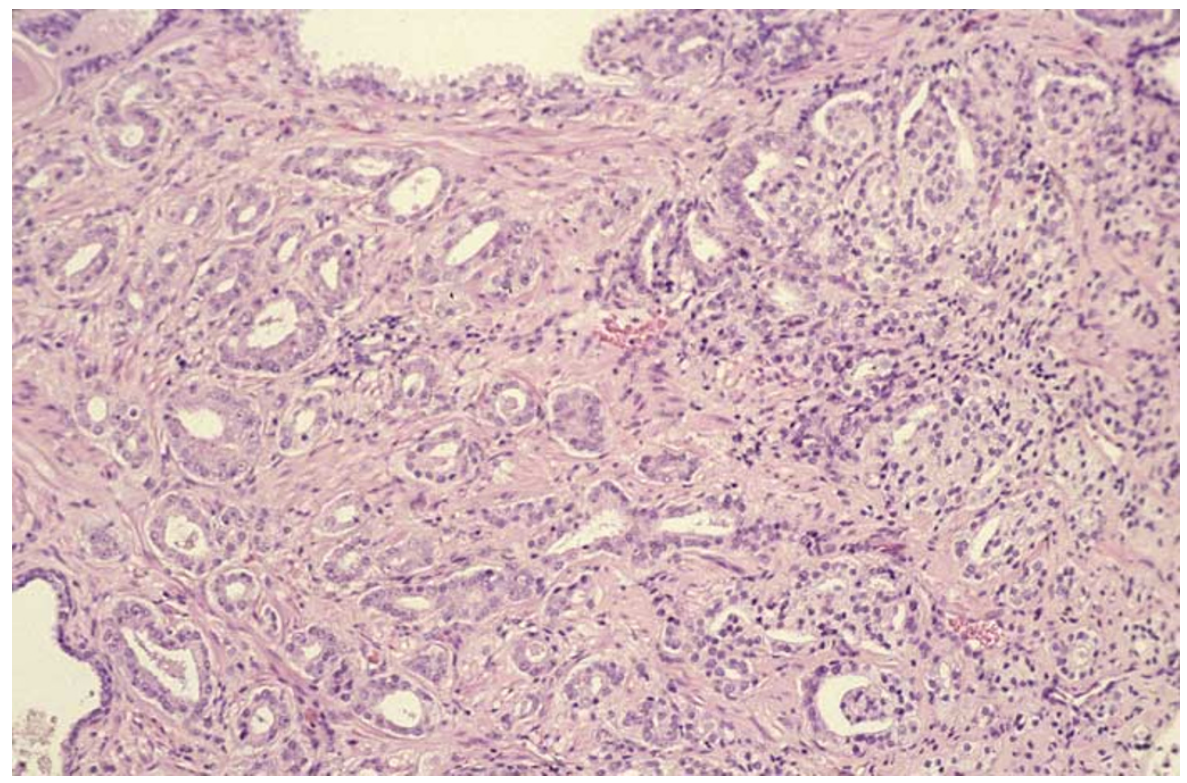

Figure 5 Gleason grade $3+4=$ score of 7 adenocarcinoma.

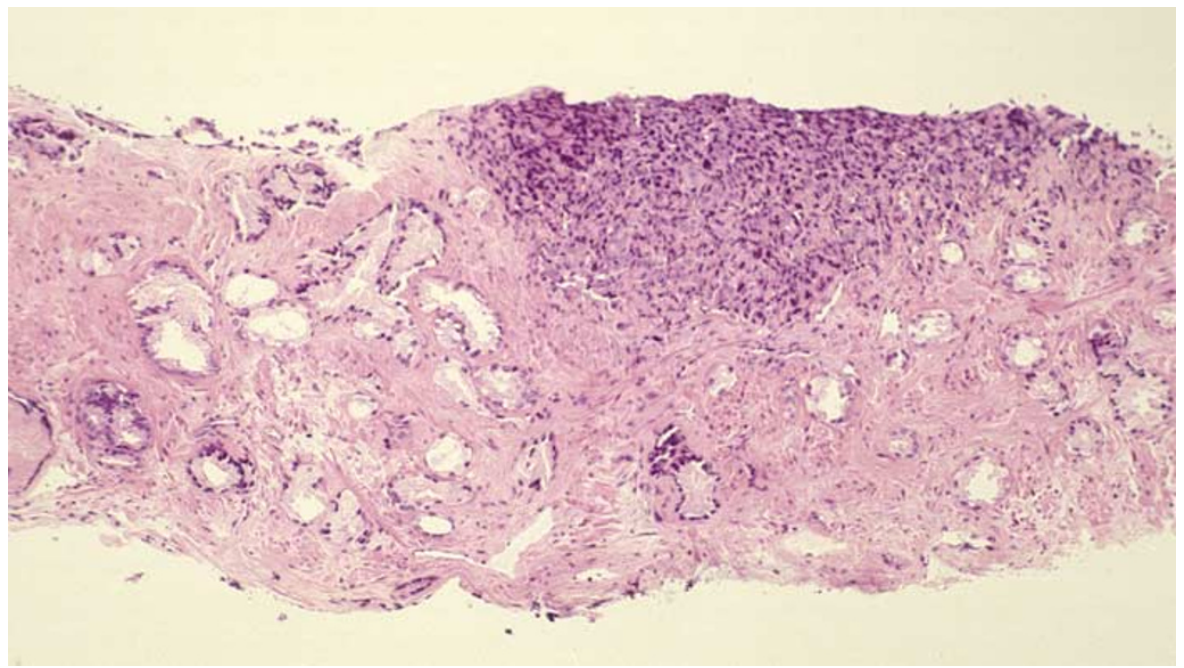

Figure 6 Gleason grade $3+5=$ score of 8 adenocarcinoma. 
conjunction with pattern 4 to yield a score of 7 (Figure 5). In Gleason's series, a composite with pattern 5 to give a score of 8 (Figure 6) was more common than a mingling with 4 to produce a score of $7,{ }^{8}$ but today Gleason score 7 is more common than 8. Overall, Gleason scores of 5-7 with embedded pattern 3 are the most common histologic grades of prostatic adenocarcinoma.

\section{Gleason Pattern 4 (Grade 4)}

A

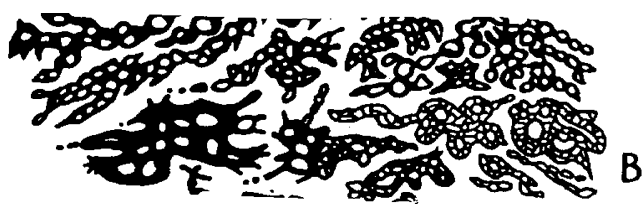

This is a high-grade and poorly differentiated carcinoma growth, with raggedly infiltrative masses, or chains or cords of malignant epithelial cells (Figure 7). The cellular arrangements can be fused microacinar, cribriform, or papillary. Cribriform and papillary pattern 4 carcinomas can resemble cribriform and papillary pattern 3 carcinomas in gland formations and papillary projections, but pattern 4 is recognized by the ragged edges or outlines of the invasive periphery compared to the smooth, pushing borders of pattern 3C. Carcinoma growing in this manner, but with cleared cytoplasm, is deemed pattern $4 \mathrm{~B}$, and can simulate renal cell carcinoma of clear cell type (hypernephroma). Thus, this variant has been termed the hypernephroid or hypernephromatoid pattern. The nuclei in pattern 4 may be deceptively bland, with little nucleomegaly and no nucleolomegaly. In these cases, highly infiltrative small, fused glands should be a clue as to the high-grade nature of the carcinoma.

Pattern 4 is most often combined with pattern 3 to yield a score of 7 , which is currently one of the most commonly assigned Gleason scores. Pure high-grade disease, where there is pure pattern 4 or mingling with pattern 5 to produce scores of 8 and 9 , is less common (Figure 8). Gleason score 8 is more common in series, such as the VACURG series, ${ }^{8}$ that includes higher stage, clinically nonorgan confined prostate cancer. Pattern 4 is hardly ever found with well-differentiated patterns 1 and 2 .

\section{Gleason Pattern 5 (Grade 5)}

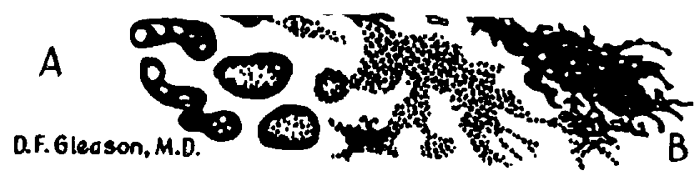

This is the most poorly differentiated pattern of prostatic carcinoma, which presents in two forms$5 \mathrm{~A}$ and $5 \mathrm{~B}$. There is no need to specify $5 \mathrm{~A}$ vs $5 \mathrm{~B}$; the distinction is solely for the purpose of grade 5 diagnostic recognition. Pattern 5A resembles the comedo type of intraductal carcinoma of the breast, with smooth, rounded masses, cords or cylinders of carcinoma. The necrosis is typically central, being surrounded by papillary, cribriform, or solid masses of carcinoma (Figure 9). The appearance can be similar to pattern 3C except for the presence of necrosis. Proteineous secretions in prostate carcinoma should not be mistaken for the tumoral cell necrosis of comedocarcinoma, where one can visualize ghost-like outlines of dead carcinoma cells, particularly at the interface of the central necrosis and the viable epithelium. Some cases of pattern 5A actually represent comedo intraductal prostatic carcinoma or in situ spread of ductal adenocarcinoma since basal cells can be observed, but in the Gleason scheme, these designations are not used, and this pattern $5 \mathrm{~A}$ is just termed a Gleason pattern 5 adenocarcinoma.

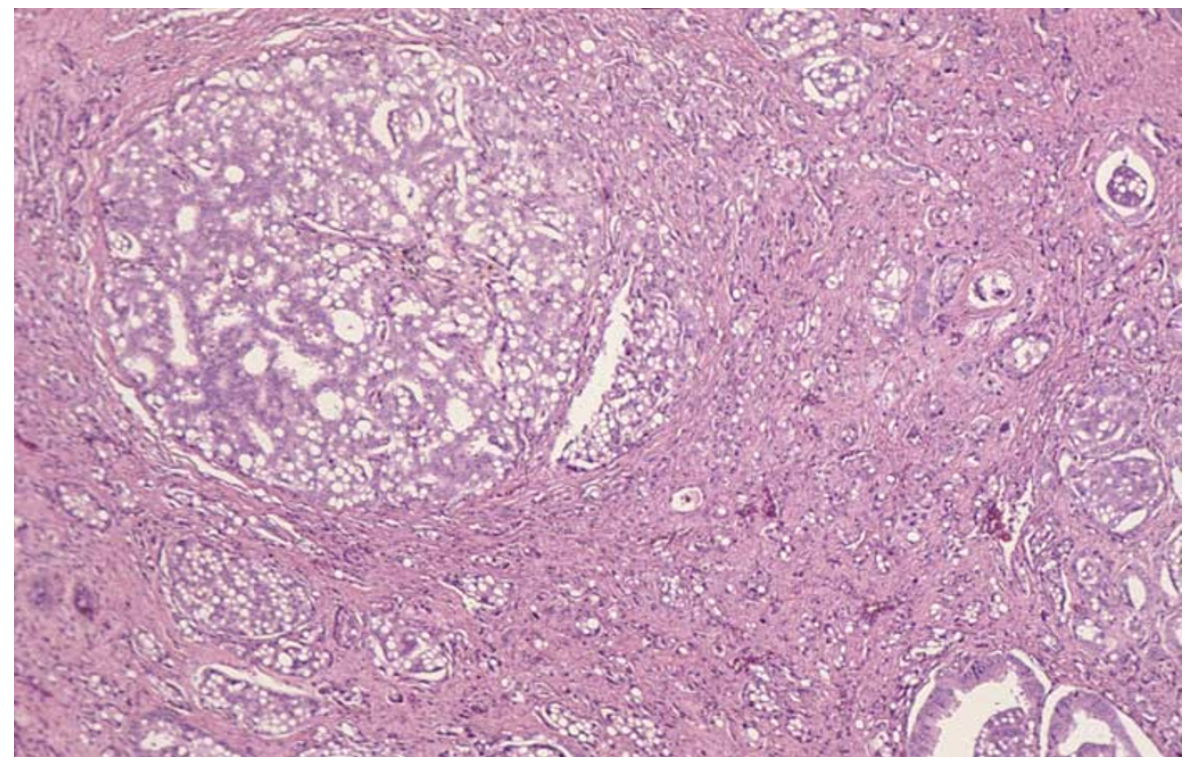

Figure 7 Gleason grade $4+4=$ score of 8 adenocarcinoma. 


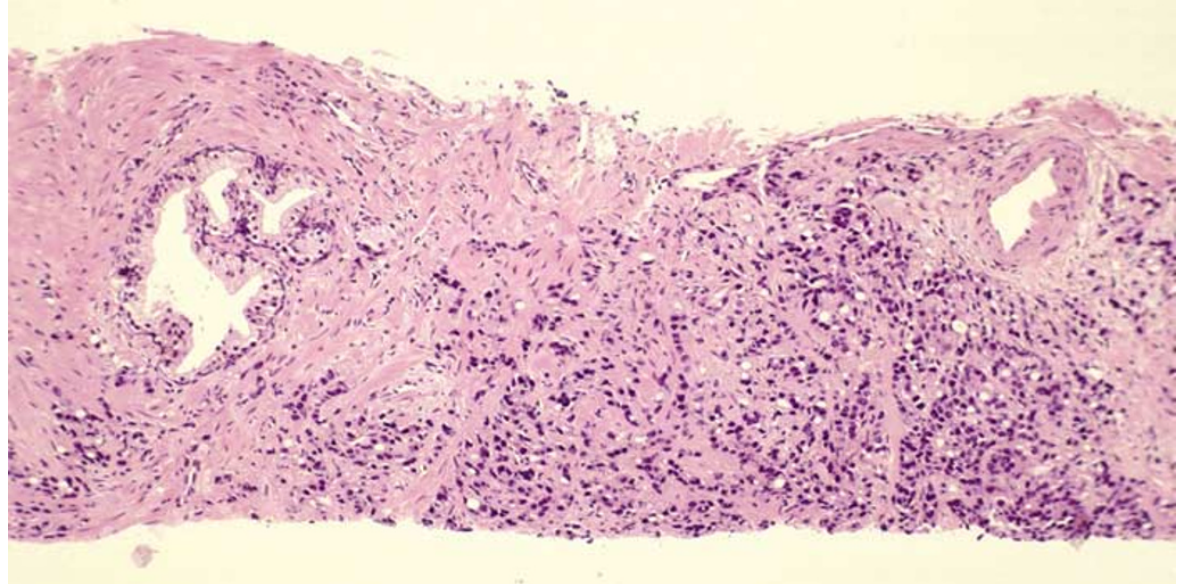

Figure 8 Gleason grade $5+4=$ score of 9 adenocarcinoma.

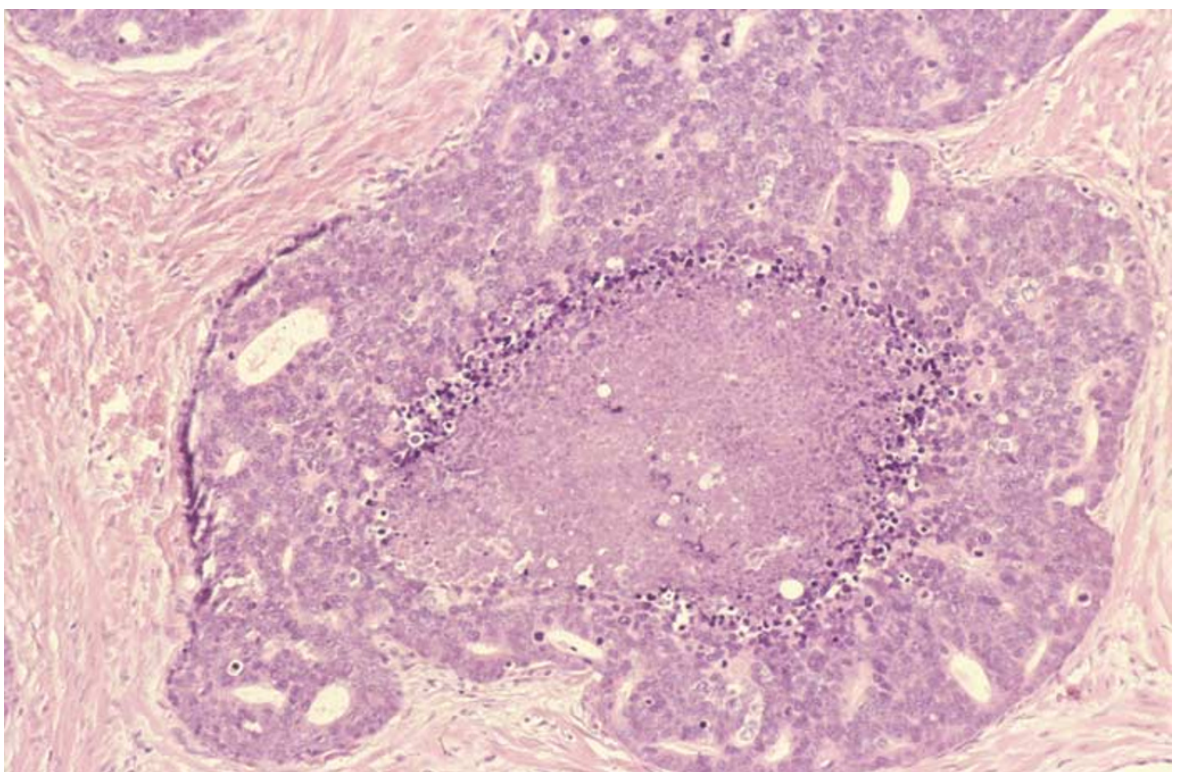

Figure 9 Gleason grade 5 comedocarcinoma.

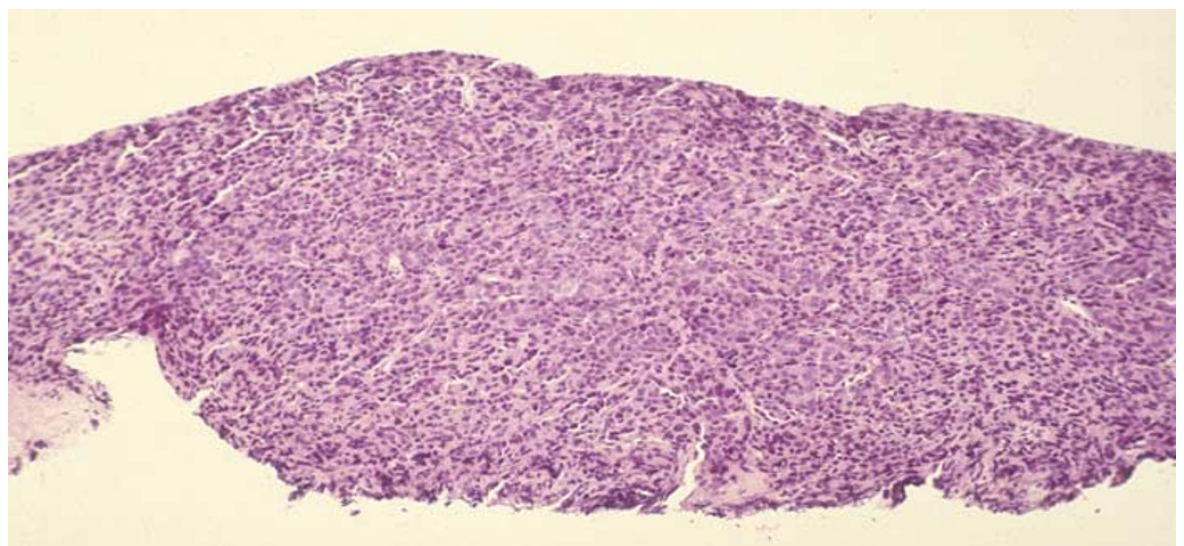

Figure 10 Gleason grade $5+5=$ score of 10 adenocarcinoma. 
Pattern 5B is comprised of ragged sheets of anaplastic adenocarcinoma cells (Figure 10). This form is so poorly differentiated that only a few small glandular lumina or signet-ring cells may be present to indicate adenocarcinoma rather than a poorly differentiated malignant neoplasm of unknown cell type.

In summary, raggedly infiltrative sheet-like growth and comedo necrosis are the hallmarks of Gleason pattern 5. Single cell tumor growth is often assumed to be high-grade carcinoma, but his pattern is not formally recognized in the Gleason system. Indeed, the only time single cells are mentioned in the Gleason publications is in the original 1966 description, ${ }^{8}$ where single cells are discussed under patterns 2 and 3. Still, if the single cells are raggedly infiltrative or of signet-ring type, then assignment of pattern 5 seems reasonable. ${ }^{26,27}$

Pattern 5 is most often found with pattern 3 , with a resultant score of 8 . Less common is pure pattern 5 or comingling with pattern 4 , to yield scores of 10 and 9 , respectively. Gleason scores 9 and 10 are seen associated with high clinical stage disease, with clinically detectable cancer outside the prostate, either locally or in the form of metastatic disease. ${ }^{8} \mathrm{In}$ only two of 2911 cases in the Gleason/VACURG series was pattern 5 detected with patterns 1 or $2 .^{8}$

\section{Gleason Grade of Histological Variants of Prostatic Carcinoma}

The Gleason system is designed for application to all untreated prostatic glandular carcinomas. Gleason specifically addressed three variants - ductal (the so-called endometrioid in the past), signet-ring cell,

Table 2 Gleason grade of histologic variants of prostatic carcinoma
Variants

Variants

Histologic variants

Ductal (endometriod) carcinoma

Signet-ring cell carcinoma

Mucinous (colloid) carcinoma

Lymphoepithelioma-like

Sarcomatoid carcinoma (carcinosarcoma)

Small cell carcinoma

Squamous cell carcinoma

Basaloid/adenoid cystic 'carcinomas'

Growth/cytologic variants

Hypernephroid (hypernephromatoid) pattern

Atrophic pattern

Pseudohyperplastic pattern

Foamy gland carcinoma

Carcinoma with Paneth-like cells

Carcinoma with oncocytic cells
Transitional cell carcinoma
Gleason pattern (grade) and small cell carcinoma ${ }^{8,10}$ (Table 2). A number of histological variants, including mucinous and sarcomatoid carcinomas, were not explicitly discussed. Recommendations for grading variants have been made. ${ }^{26,28}$ Newly described growth and/or cytological variants, including atrophic pattern adenocarcinoma, pseudohyperplastic carcinoma, foamy gland carcinoma, carcinoma with Paneth-like (neuroendocrine cells), and carcinoma with oncocytic cells, can readily be graded using the Gleason pattern technique, except for the pseudohyperplastic pattern. ${ }^{29,30}$ In our experience, ${ }^{29}$ this variant is most often associated with Gleason patterns 2 and 3 and in a second series, ${ }^{30}$ the linkage was usually with pattern 3. Squamous cell and urothelial (transitional) cell carcinomas of the prostate should not be graded by the Gleason method.

\section{Grading in Fine-Needle Aspirates}

Attempts have been made to apply Gleason grading to fine-needle aspiration biopsy samples of prostatic carcinoma, but since epithelial-stromal relationships are not preserved in these specimens, this is not advisable. Rather, traditional cytologic grading as well, moderately, or poorly differentiated, is recommended. ${ }^{31}$

\section{Grading in Different Prostatic Tissue Samples}

Gleason grading should be performed in all prostatic tissue samples, including needle core biopsy specimens. Indeed, of Gleason's original series of 2911 patients, $60 \%$ were graded solely on the basis of a needle biopsy. ${ }^{8}$ A Gleason grade should be assigned even to needle biopsy cases with minimal prostatic carcinoma, defined as less than $1 \mathrm{~mm}$ of tumor. ${ }^{32,33}$ Of importance, a small amount of carcinoma in needle biopsy tissue should not be equated with well-differentiated Gleason score 2-4 adenocarcinoma. Most minimal adenocarcinomas in needle biopsy tissue are intermediate Gleason grade, usually of a score of 6. Comparisons of Gleason grade in needle biopsy with Gleason grade in the matched whole prostate gland indicate exact correlation in $43 \%$ of cases (range $20-88 \%$ ) and agreement to within \pm 1 score unit in $77 \%$ of 3789 cases (range 62-97\%) (reviewed in Humphrey). ${ }^{4}$ Undergrading of tumor in the needle biopsy, with a higher Gleason score in the matched whole gland, is the most common problem, occurring, on average, in $42 \%$ of all cases. Overgrading of carcinoma in needle biopsy tissue also takes place, but with a much lower mean of $15 \%$ of all cases. For needle biopsy cases, there are several sources of grading error, including difficulty in appreciation of an infiltrative growth pattern, tissue sampling error (related to the small amount of tissue supplied by needle biopsy and grade heterogeneity), tissue distortion, pathologist experience, and observer variability.
Variable (most 3)

Most 2-3

Variable

(most 3-4)

Variable

Variable

3-4: without
necrosis
$5:$ with necrosis
5
4
5
5 (glands graded
separately)
Not applicable
Not applicable
Not applicable
Not applicable

4
Variable
(most 3)
Most 2-3
Variable
(most 3-4)
Variable
Variable


Assignment of Gleason grade to larger tissue samples, including TURP chips, and open (simple) and radical prostatectomy specimens is often more straightforward than in needle biopsy cases. A distinctive characteristic of carcinoma grade in TURP chips and open (simple) enucleation prostatectomy specimens is that well-differentiated Gleason score 2-4 adenocarcinomas are much more common in these tissue specimens compared to needle biopsies and radical prostatectomy specimens. Cautery artefact can generate difficulty in grading carcinoma in TURP chips. The Gleason grade of incidental stage $\mathrm{T} 1 \mathrm{a} / \mathrm{b}$ carcinoma tends to be somewhat less than the grade in the whole gland since the TURP procedure samples the transition zone where lower-grade carcinomas arise.

\section{Reproducibility}

The Gleason grading system, like all histological grading methods, possesses an inherent degree of subjectivity. Intraobserver and interobserver variability does exist. ${ }^{4,34,35}$ Recent data suggest that for needle biopsy grading, pathologist training and experience $^{34}$ can influence the degree of interobserver agreement. In one study, 41 general pathologists exhibited moderate agreement, with a kappa coefficient of $0.435 .{ }^{35}$ For general pathologists, the main difficulty was undergrading. Those pathologists with better interobserver agreement had learned the Gleason grading system at a meeting or course. Experience and interest in urologic pathology resulted in enhanced interobserver agreement, with kappa coefficients of 0.6-0.7, indicating substantial agreement, for 9 of 10 urologic pathologists. In this investigation, ${ }^{34}$ there were several (eight of 46) cases which were problematic in that a consensus could not be reached on grade assignment. These cases included low-grade tumors, tumors with small cribriform proliferations, and 'borderline' cases, which exhibited structures at the border between two patterns. For pathologists, improvement in Gleason grading of carcinoma can be achieved by participation in educational courses at meetings and by use of tutorial programs ${ }^{36,37}$ including web-site programs (at www.pathology.jhu.edu/prostate ${ }^{36}$ and http://www.pathology.ks.se/egevad/gleason.html ${ }^{37}$ ).

\section{Grading in Metastatic Deposits}

Gleason grading of prostatic carcinoma outside the prostate and in metastatic deposits has been reported, but the Gleason system was not originally designed for this purpose as it is based upon epithelial (carcinoma)-stromal architectural relationships within the prostate.

\section{Grading after Radiation and Hormonal Therapy}

In general, the Gleason grading system should be applied only to tumor that shows no evidence of treatment effect. For radiation therapy cases, where there is no evidence or minimal evidence of therapy effect, Gleason grading may be utilized. Hormonal therapy can cause pattern alterations resembling high Gleason grades. Overall, the consensus view is that one should not report histologic grade after hormonal therapy. ${ }^{38}$

\section{Relationship of Gleason Grade to Pathologic and Clinical End points}

Increasing Gleason grade is directly related to a number of histopathological end points, including lymphvascular space invasion by carcinoma, tumor size, positive surgical margins, and pathological stage, including risk of extraprostatic extension and metastasis (reviewed in Humphrey ${ }^{4}$ ).

Prediction of pathologic stage by needle biopsy Gleason grade alone is possible but is not absolutely accurate for the individual patient. So, patients with lower-grade (Gleason score 2-6) carcinomas are still at risk for having cancer spread outside the prostate, and not all patients with a high-grade carcinoma component (Gleason score 7-10) will have carcinoma extension beyond the confines of the prostate gland. Clinically, needle biopsy Gleason grade is usually combined with other pretreatment factors, such as serum total PSA, \% free PSA, local clinical $\mathrm{T}$ stage, and amount of tumor in needle biopsy, to predict pathologic stage. Perhaps the most commonly used data clinically are the so-called 'Partin tables', ${ }^{39}$ which combine needle biopsy Gleason grade, serum PSA, and clinical stage to provide estimates of risk for extraprostatic extension, seminal vesicle invasion, and lymph node metastasis. (These tables are available on the web at http:// prostate.urol.jhu.edu/Partin_tables/.) Another nomogram available on the web (at www.mskcc.org/ mskcc/html/6155.cfm) uses biopsy Gleason grade, pretreatment PSA, clinical stage, and treatment information to calculate pathologic stage, and 5year progression-free probability for radical prostatectomy, external beam radiation therapy, or brachytherapy.

Needle biopsy Gleason grade has also been incorporated into models to predict potentially clinically 'insignificant', 'unimportant', or 'harmless' prostate cancer, based on pathologic features in the whole gland. ${ }^{23,40}$ These models are not perfect, but can provide an estimate of risk for the patient having a small, organ-confined cancer without a high-grade Gleason pattern in the whole gland.

Histological grade of prostatic carcinoma is one of the most powerful, if not the dominant, predictor of clinical outcome for patients with this cancer. A number of clinical end points have been linked to histological grade, including clinical stage, response to different therapies, PSA ('biochemical') failure progression to metastatic disease, and survival, including prostate cancer-specific survival (Figure 11) and overall survival. ${ }^{8,18-20,41}$ 
Age at diagnosis, yr
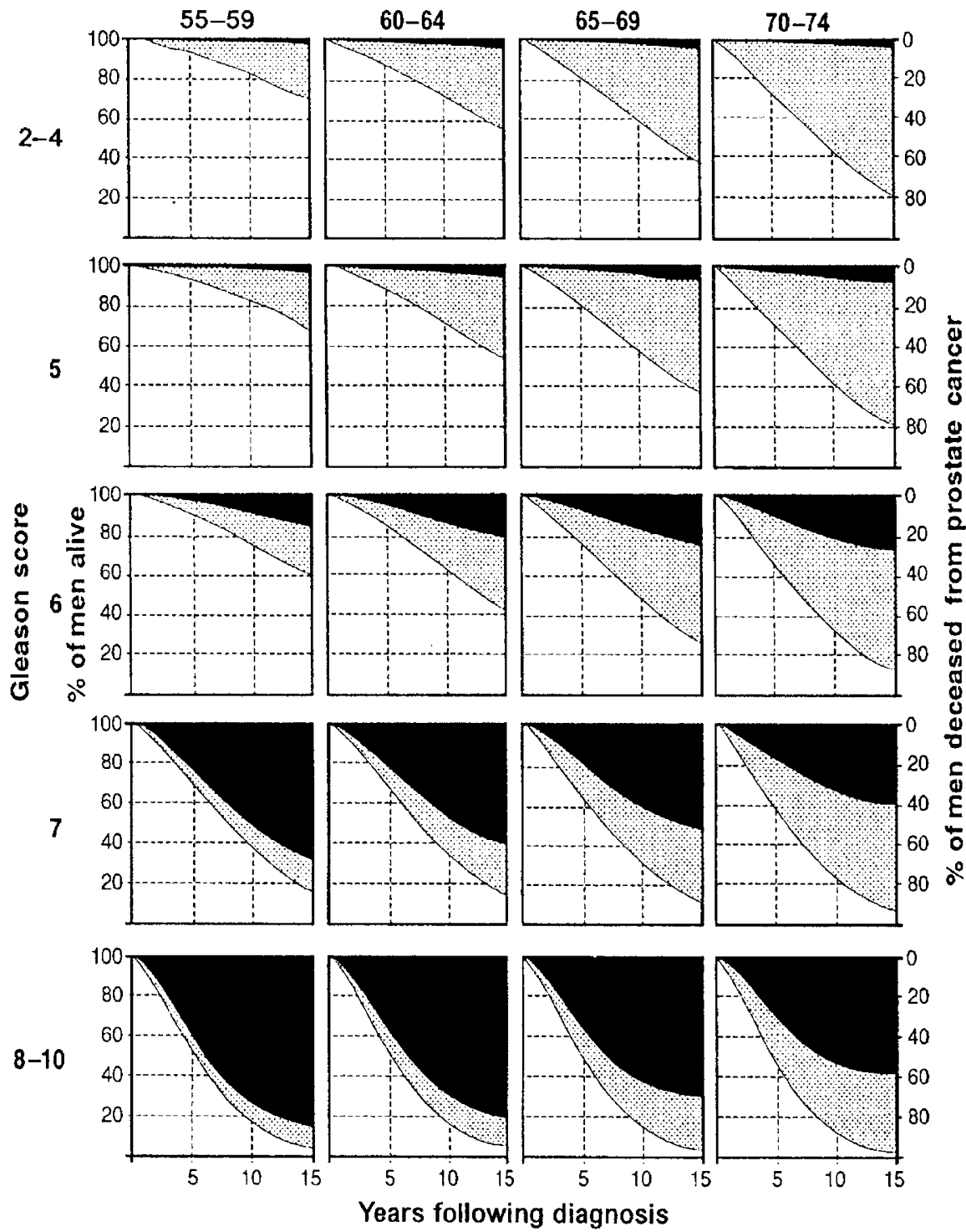

Figure 11 Survival (white lower band) and cumulative mortality due to prostate cancer (black upper band) and to other causes (light gray middle band) from 0 to 15 years after diagnosis, stratified by age at diagnosis and Gleason score. The prostate cancer patients were managed conservatively, with either no treatment or treatment with hormonal therapy. (From reference Albertsen et al. ${ }^{19}$ : JAMA, 1998, vol. 280, page 978, with permission from American Medical Association. Copyright 1998, American Medical Association. All rights reserved.)

Needle biopsy Gleason grade is routinely used to determine eligibility for clinical trials and plan treatment for patients. Men with lower Gleason scores are more likely to elect watching waiting surveillance as initial management. ${ }^{42}$ Needle biopsy Gleason scores can be used in conjunction with serum PSA and clinical stage to plan for the type of radiation therapy and whether to administer hormonal therapy with radiation therapy. As noted above, needle biopsy Gleason score can also be used with serum PSA and clinical stage to predict response to radiotherapy or to radical prostatectomy. Some nomograms are available as software programs for handheld computers (personal digital assistants), such that in a matter of seconds, by plugging in needle biopsy Gleason grade, serum PSA level, and clinical stage, one can find out what the likelihood is, for that individual patient, of disease-free survival 5 years after radical prostatectomy or radiation therapy.

Radical prostatectomy histological grade, including Gleason grade, is one of the most powerful predictors of failure after surgery. It is the presence of high-grade (Gleason pattern 4 or 5) disease that harbors the greatest risk for the patient. ${ }^{8,18,20,43,44}$ The presence of any high-grade carcinoma, even a tertiary component comprising just a few percent of the total amount of tumor, has a deleterious 
impact on cure rates. ${ }^{16}$ The amount or percentage of high-grade carcinoma may have an impact on the chance for cure. ${ }^{44}$ So, Gleason score 7 carcinoma patients have an outcome intermediate between Gleason score 5-6 and 8-10. Within the Gleason score 7 category, a $4+3$ score, with more 4 pattern than 3 , appears to carry a worse prognosis than a $3+4$ score, where pattern 3 dominates.

Radical prostatectomy Gleason grade can be used in models to predict high risk for recurrence after surgery. These models typically incorporate Gleason score, preoperative serum PSA, and pathologic stage, with or without tumor volume, and margin status. ${ }^{44,45}$ This information can be used to help stratify patients for consideration of closer surveillance and/or adjuvant therapy. One model predicts whether a rising PSA after surgery is caused by a local disease or distant metastasis. This program (called Partin II Calculation) is available on the web (at http:// www.prostatepointers.org/prostate/partin/partin2-

form.html) and is based on radical prostatectomy Gleason score and postoperative PSA velocity.

Gleason score of the primary tumor appears to be of prognostic value in the setting of pelvic lymph node metastasis, but is of uncertain worth in the setting of distant and bony metastasis.

\section{Experimental Approaches}

Grade, as a measure of intrinsic biological aggressiveness, may be assessed in the future by both structural (morphological and morphometric) and functional means. One proposed morphological approach is quantitation of amount of high-grade (percentage Gleason pattern 4 or 5) carcinoma. ${ }^{44,46}$ In TURP chips, the percentage of score $4 / 5$ was the most powerful predictor of death for prostate cancer. ${ }^{46}$ The percentage of a tumor that is Gleason pattern 4 or $5(4 / 5)$ in the whole gland has been related to cancer volume, the presence of lymph node metastasis, and progression after radical prostatectomy. Thus, this factor may be utilized in the reporting of grade in radical prostatectomy specimens in the future, but validation at other institutions and the questions of reliability of the estimate (interobserver agreement) and how best to quantitate \% 4/5 disease must be addressed. It is not clear how to quantitate \% 4/5 cancer: In one study, ${ }^{44}$ $10 \%$ increments were used while a four-tiered categorization $(<5 \%, 5-24 \%, 25-49 \%,>49 \%)$ has also been used. Reporting of percentage Gleason grade $4 / 5$ in cancer in needle biopsy has been advocated, ${ }^{47}$ but only limited data have been published on the relationship of percentage Gleason pattern 4/5 in carcinoma in needle core tissue and pathologic and clinical end points. The percentage Gleason pattern $4 / 5$ in needle cores is related to percentage of that pattern in the whole gland (in radical prostatectomy specimens), but the correlation is variable. Overall, use of the $\% 4 / 5$ parameter in needle biopsy seems to be limited by a high falsenegative rate. ${ }^{48}$ It does not appear to provide additional information beyond standard Gleason score in the prediction of cancer progression after radical prostatectomy. So, the amount of carcinoma comprised of high-grade Gleason grade pattern 4 or 5 has potential for adding information to standard Gleason grade assignment in TURP and radical prostatectomy tissues, while its utility in needle core tissue is currently uncertain.

Quantitative measures of nuclear abnormalities have also been forwarded as grading tools. These abnormal features can be divided into morphometric features-as in quantitation of DNA content, and textural attributes, related to chromatin patterns. ${ }^{49}$ Morphometric descriptors include nuclear area, nuclear diameter, nucleolar area, nuclear roundness, elongation factor, ellipticity, form factor, chain code, and percent convex area fraction. These features have been used alone or in combination with other factors in linkage with pathological and clinical end points. However, none of these features is an established and independent prognosticator. For example, the data on nuclear roundness and DNA content (ploidy) are conflicting. ${ }^{49}$ Although quantitative, the methods used to measure nuclear abnormalities are time consuming and expensive, typically requiring a digital image analysis system. Moreover, multiple factors, such as method of tissue procurement, fixation, processing, and section preparation, could affect nuclear features. Additional potential problems with quantitative digital image analysis include reproducibility, subjectivity in field selection, and lack of standardized methods. For these reasons, quantitative measures of nuclear changes may be difficult to capture on a routine basis.

Structural alterations in carcinoma cell DNA, RNA, and protein have also been linked to pathologic and clinical end points in attempts to predict carcinoma aggressiveness, but these are currently experimental. Genotypic grading of DNA abnormalities might one day be used in conjunction with the current phenotypic grading.

Functional gene expression profiles of prostatic carcinoma might provide information on carcinoma aggressiveness, or grade, but this is currently an experimental tool. Historically, the expression of individual genes has been assessed one or a few at a time, but the simultaneous characterization of the expression of thousands of genes by gene chip microarray analysis hold great promise for the future in improving grading of prostate cancer. Indeed, in one recent gene expression profiling study, there was a readily detectable and statistically significant signature of Gleason score, and a suggestion that such profiling might identify a subset of intermediate-grade tumors with more aggressive clinical behavior. $^{50}$ Already, gene expression profiling has identified aberrantly expressed genes whose expression was found to provide added value to grade in prediction of outcome. ${ }^{51}$ 


\section{Reporting}

Histologic grade should be reported for untreated adenocarcinoma in every prostatic tissue sample. The Gleason grade should be utilized and the primary pattern plus secondary pattern equals score should be recorded. Another scheme may be reported in addition to the Gleason grade, if desired, but the Gleason grade should always be included in the report.

For needle biopsy cores, histologic grade should be assigned to carcinoma in separately submitted tissues (containers), designated by site. This pertains mainly to needle biopsy specimens that are submitted separately. It has been recommended that for needle biopsies with different Gleason grades in different, separately submitted needle cores, a composite score be rendered. ${ }^{17}$ In one study, ${ }^{52}$ the composite or global Gleason score for six needle core tissue samples from different locations had the strongest association with radical prostatectomy pT3 disease and margin status compared to the highest Gleason score for any single core or weighted Gleason score (the average Gleason score weighted by tumor amount in all cores). Further data are needed, but these data do support rendering a composite, overall, or global Gleason score for each case. Another recent study presented data that each core should also be given a separate grade. ${ }^{53}$ In needle biopsy tissue, if there is one Gleason pattern, it should be doubled to yield a score. High-grade pattern 4 or 5 should be incorporated into the score, even if it represents a tertiary pattern. Gleason grade should be provided for all carcinomas in needle biopsy, even for minute, minimal, or limited carcinomas. Gleason grade reporting in TURP chips and enucleation specimens should follow the standard Gleason method of reporting the predominant pattern as the primary grade and the second most common pattern as the secondary grade. If a tertiary Gleason pattern 4 or 5 is detected, it should definitely be noted. ${ }^{46}$ Radical prostatectomy Gleason grade should be assigned in standard fashion, with the most common and the secondary Gleason patterns in the whole gland used to determine the primary and secondary Gleason grades. There are published recommendations to grade only the 'dominant nodule'28 or to report separate grades for separate tumors in the whole gland, ${ }^{17}$ but many prostate glands lack a dominant nodule and no data exist to support reporting of separate tumors. A tertiary high-grade component, when present, should definitely be reported since this has an impact on prognosis. ${ }^{16}$ The recommendation that is evidence-based ${ }^{16}$ is to keep the original Gleason score (based on the first most common and second most common patterns), with a notation on the presence of a tertiary high-grade component.

\section{Prognostic factors for prostatic carcinoma}

Prognosis for patients with prostate cancer may be defined as the prediction of future behavior of established malignancy, either in the absence of or after application of therapy. ${ }^{54}$ Factors predicting prognosis may be divided into two categories: ${ }^{54}$

1. Prognostic factors $=$ those that predict relapse or progression independent of future treatment effects.

2. Predictive factors $=$ those that predict response or resistance to a specific therapy.

Currently, there are no predictive factors or markers that are utilized in prostatic carcinoma. For example, unlike breast carcinoma estrogen receptor status, which can be used to predict response to tamoxifen, androgen receptor status in prostatic carcinoma does not predict response to hormonal therapy.

Here, we briefly focus on prognostic factors, with stratification into categories of established factors recommended for routine reporting (category I), factors with promise or recommended despite incomplete data (category II), and factors that are not currently recommended due to insufficient evidence (category III) (Table 3). ${ }^{55,56}$

Category I histopathological factors include pathologic stage and surgical margin status of radical prostatectomy specimens, and Gleason histologic grade in all prostatic tissue samples.

Category II factors that are recommended for reporting include histologic subtypes of prostatic carcinoma, and tumor amount in needle biopsy and radical prostatectomy specimens. Tumor amount in

Table 3 Prognostic factors for prostate cancer: College of American Pathologists (CAP) and World Health Organization (WHO) Recommendations ${ }^{\mathrm{a}}$

Category I: Recommended for routine reporting ${ }^{\mathrm{b}}$

TNM stage

Histological grade (Gleason)

Surgical margin status

Perioperative serum PSA

Category II: Factors with promise or recommended despite incomplete data

DNA ploidy

Histologic type

Tumor amount in needle biopsy tissue (recommended)

Tumor amount in radical prostatectomy specimens

(recommended)

Category III: Not currently recommended due to insufficient evidence

Genetic markers

Neuroendocrine markers

Proliferation markers, apoptosis

Perineural invasion

Vascular/lymphatic invasion

Microvessel density

Nuclear morphometry

Androgen receptors

${ }^{\mathrm{a}}$ From references Bostwick et al. ${ }^{55}$ and Bostwick and Foster ${ }^{56}$.

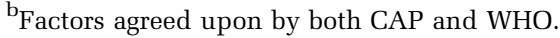


needle biopsy tissue should be reported and may be quantitated as number of positive cores out of total number of cores, total length (mm) of tumor in all cores, greatest percentage of a single core involved by carcinoma, and total or overall percentage of biopsy tissue involvement (which can be assessed by simple visual inspection). Data exist to suggest that it may be important to report more than one measure of tumor extent in needle biopsy tissue. ${ }^{57,58}$ For radical prostatectomy specimens, it has been recommended that tumor size be reported as percentage of cancer in the prostate. ${ }^{55,59}$ Additionally, one could measure size of a dominant nodule in two dimensions and indicate number of blocks involved by tumor over the total number of blocks submitted. ${ }^{17}$ DNA ploidy is within category II, but currently it is felt that the data are not compelling enough to warrant routine use. ${ }^{55}$

Category III factors are not currently recommended for reporting due to insufficient evidence. The data on perineural invasion as a prognostic indicator are decidedly mixed (reviewed in Bismar et $a 5^{58}$ ). There is a large number of morphometric, immunophenotypic, and genotypic markers that have been forwarded as prognosticators but these are currently experimental. ${ }^{60}$ Gene expression profiling by analysis of the transcriptome and proteome harbor potential to provide significant prognostic information. ${ }^{50,51}$ To prove clinical utility of any new potentially important prognostic marker, including molecular markers, it will need to be incorporated and tested in prospective, randomized, controlled clinical trials and will need to provide added, independent value, in multivariate analysis, beyond established prognostic indicators, including pathologic stage and Gleason grade.

\section{References}

1 Brown L, (ed). The New Shorter Oxford English Dictionary. Clarendon Press: Oxford, 1993, p 1125.

2 Gardner. Jr WA. Histologic grading of prostate cancer: a retrospective and prospective overview. Prostate 1982;3:555-561.

3 Broders AC. Squamous cell epithelioma of the lip. JAMA 1920;74:656-664.

4 Humphrey PA. Grading of prostatic carcinoma. In: Prostate Pathology. ASCP Press: Chicago, 2003, pp 338-374; (Chapter 15).

5 Gleason DF. Classification of prostatic carcinoma. Cancer Chemother Rep 1966;50:125-128.

6 Mellinger GT, Gleason D, Bailar. III J. The histology and prognosis of prostatic cancer. J Urol 1967;97:331-337.

7 Gleason DF, Mellinger GT. The Veterans Administration Cooperative Urological Research Group. Prediction of prognosis for prostatic adenocarcinoma by combined histological grading and clinical staging. J Urol 1974;111:58-64.

8 Gleason DF. The Veterans Administration Cooperative Urological Research Group. Histologic grading and clinical staging of prostatic caricnoma. In: Tannen- baum M (ed). Urologic Pathology: The Prostate. Lea \& Febiger, Philadelphia, 1977, pp 171-197; (Chapter 9).

9 Gleason DF. Histologic grading of prostate cancer: a perspective. Hum Pathol 1992;23:273-279.

10 Gleason DF. Histologic grading of prostatic carcinoma. In: Bostwick DG (ed). Pathology of the Prostate. Churchill Livingstone: New York, 1990, pp 83-93.

11 Mostofi FK, Sesterhenn I, Sobin LH. Histological typing of prostate tumours. In: International Histological Classification of Tumours, No. 22. Geneva: World Health Organization, 1980.

12 Mostofi FK. Grading of prostatic carcinoma. Cancer Chemother Rep 1975;59:111-117.

13 Aihara M, Wheeler TM, Ohori M, Scardino PT. Heterogeneity of prostate cancer in radical prostatectomy specimens. Urology 1994;43:60-66.

14 McGowan DG, Bain GO, Hanson J. Evaluation of histological grading (Gleason) in carcinoma of the prostate: adverse influence of highest grade. Prostate 1983;4:111-118.

15 Ruijter ET, van de Kaa CA, Schalken JA, et al. Histological grade heterogeneity in multifocal prostate cancer. Biological and clinical implications. J Pathol 1996;180:295-299.

16 Pan CC, Potter SR, Partin AW, Epstein JI. The prognostic significance of tertiary Gleason patterns of higher grade in radical prostatectomy specimens: a proposal to modify the Gleason grading system. Am J Surg Pathol 2000;24:563-569.

17 Srigley JR, Amin MB, Bostwick DG, et al. Updated protocol for the examination of specimens from patients with carcinomas of the prostate gland. Arch Pathol Lab Med 2000;124:1034-1039.

18 Epstein JI, Partin AW, Sauvageot J, et al. Prediction of progression following radical prostatectomy: a multivariate analysis of 721 men with long-term follow-up. Am J Surg Pathol 1996;20:286-292.

19 Albertsen PC, Hanley JA, Gleason DF, et al. Competing risk analysis of men aged 55 to 74 years at diagnosis managed conservatively for clinically localized prostate cancer. JAMA 1998;280:975-980.

20 Barry MJ, Albertsen PC, Bagshaw MA, et al. Outcomes for men with clinically nonmetastatic prostate carcinoma managed with radical prostatectomy, external beam radiotherapy, or expectant management. Cancer 2001;91:2302-2314.

21 Epstein JI. Gleason score 2-4 adenocarcinoma of the prostate on needle biopsy. A diagnosis that should not be made. Am J Surg Pathol 2000;24:477-478.

22 Humphrey PA, Vollmer RT. Intraglandular tumor extent and prognosis in prostatic carcinoma: application of a grid method to prostatectomy specimens. Hum Pathol 1990;21:799-804.

23 Humphrey PA, Keetch DW, Smith DS, et al. Prospective characterization of pathological features of prostatic carcinoma detected via serum prostate specific antigen based screening. J Urol 1996;155: 816-820.

24 Rubin MA, de La Taille A, Bagiella E, et al. Cribriform carcinoma of the prostate and cribriform prostatic intraepithelial neoplasia: incidence and clinical implications. Am J Surg Pathol 1998;22:840-848.

25 McNeal JE, Yemoto CEM. Spread of adenocarcinoma within prostatic ducts and acini. Am J Surg Pathol 1996;20:802-814.

26 Bostwick DG. Grading prostate cancer. Am J Clin Pathol 1994;102(Suppl 1):S38-S56. 
27 Allsbrook. Jr WC, Mangold KA, Yang X, et al. The Gleason grading system: an overview. J Urol Pathol 1999;10:141-157.

28 Amin MB, Grignon DJ, Humphrey PA, et al. Gleason Grading of Prostate Cancer: a Contemporary Approach. Lippincott Williams and Wilkins: New York, 2004, pp 60-82; (Chapter 3).

29 Humphrey PA, Kaleem Z, Swanson PE, et al. Pseudohyperplastic prostatic adenocarcinoma. Am J Surg Pathol 1998;22:1239-1246.

30 Levi AW, Epstein JI. Pseudohyperplastic prostatic adenocarcinoma on needle biopsy and simple prostatectomy. Am J Surg Pathol 2000;24:1039-1046.

31 DeMay RM. Prostate. In: The Art and Science of Cytopathology. ASCP Press: Aspiration Cytology. Chicago, 1996, pp 1135-1155.

32 Thorson P, Vollmer RT, Arcangeli C, et al. Minimal carcinoma in prostate needle biopsy specimens: diagnostic features and radical prostatectomy followup. Mod Pathol 1998;11:543-551.

33 Steinberg DM, Sauvageot J, Piantadosi S, et al. Correlation of needle biopsy and radical prostatectomy Gleason grade in academic and community settings. Am J Surg Pathol 1997;21:566-576.

34 Allsbrook. Jr WC, Mangold KA, Johnson MH, et al. Interobserver reproducibility of Gleason grading of prostatic carcinoma: Urologic pathologists. Hum Pathol 2001;32:74-80.

35 Allsbrook. Jr WC, Mangold A, Johnson $\mathrm{MH}$, et al. Interobserver reproducibility of Gleason grading of prostatic carcinoma. General pathologist. Hum Pathol 2001;32:81-88.

36 Kronz JD, Silberman MA, Allsbrook. Jr WC, et al. A web-based tutorial improves practicing pathologists' Gleason grading of images of prostate carcinoma specimens obtained by needle biopsy:validation of a new medical education paradigm. Cancer 2000;89: 1818-1823.

37 Egevad L. Reproducibility of Gleason grading of prostate cancer can be improved by the use of reference images. Urology 2001;57:291-295.

38 Algaba F, Epstein JI, Aldape HC, et al. Assessment of prostate carcinoma in core needle biopsy-definition of minimal criteria for the diagnosis of cancer in biopsy material. Cancer 1996;78:376-381.

39 Partin AW, Kattan MW, Subong ENP, et al. Combination of prostate-specific antigen, clinical stage, and Gleason score to predict pathological stage of localized prostate cancer. A multi-institutional update. JAMA 1997;277:1445-1451.

40 Noguchi M, Stamey TA, McNeal JE, et al. Relationship between systematic biopsies and histological features of 222 radical prostatectomy specimens: lack of prediction of tumor significance for men with nonpalpable prostate cancer. J Urol 2001;166:104-109.

41 Egevad L, Granfors T, Karlberg L, et al. Prognostic value of the Gleason score in prostate cancer. BJU Int 2002;89:538-542.

42 Koppie TM, Grossfeld GD, Miller D, et al. Patterns of treatment of patients with prostate cancer initially managed with surveillance: Results from the CaPSURE database. J Urol 2000;164:81-88.

43 Vollmer RT, Humphrey PA. The relative importance of anatomic and PSA factors to outcomes after radical prostatectomy for prostate cancer. Am J Clin Pathol 2001;116:864-870.
44 Stamey TA, McNeal JE, Yemoto CM, et al. Biological determinants of cancer progression in men with prostate cancer. JAMA 1999;281:1395-1400.

45 Kattan MW, Wheeler TM, Scardino PT. Postoperative nomogram for disease recurrence after radical prostatectomy for prostate cancer. J Clin Oncol 1999;17: 1499-1507.

46 Egevad L, Granfors T, Karlberg L, et al. Percent Gleason grade $4 / 5$ as prognostic factor in prostate cancer diagnosed at transurethral resection. J Urol 2002;168: 509-513.

47 Stamey TA. Making the most out of six systematic sextant biopsies. Urology 1995;45:2-12.

48 Rubin MA, Mucci NR, Manley S, et al. Predictors of Gleason pattern $4 / 5$ prostate cancer on prostatectomy specimens. Can high grade tumor be predicted preoperatively? J Urol 2001;165:114-118.

49 Van der Poel HG, Schaafsma HE, Vooijs GP, et al. Quantitative light microscopy in urological oncology. J Urol 1992;148:1-13.

50 Singh D, Febbo PG, Ross K, et al. Gene expression correlates of clinical prostate cancer behavior. Cancer Cell 2002;1:203-209.

51 Dhanasekaran SM, Barrette TR, Ghosh D, et al. Delineation of prognostic biomarkers in prostate cancer. Nature 2001;412:822-826.

52 Dunn RL, Shah R, Zhou M, et al. Global Gleason score, highest core Gleason score, or weighted Gleason score: what Gleason score should be reported in prostate needle biopsies? Mod Pathol 2002;15:161 (abstract).

53 Kunz GM, Epstein JI. Should each core with prostate cancer be assigned a separate Gleason score? Hum Pathol 2003;34:911-914.

54 Hayes DF, Bast RC, Desch CE, et al. Tumor marker grading system: a framework to evaluate clinical utility of tumor markers. J Natl Cancer Inst 1996;88: 1456-1466.

55 Bostwick DG, Grignon DJ, Hammond EH, et al. Prognostic factors in prostate cancer. College of American Pathologists Consensus Statement 1999. Arch Pathol Lab Med 2000;124:995-1000.

56 Bostwick DG, Foster CS. Predictive factors in prostate cancer: current concepts from the 1999 College of American Pathologists Conference on Solid Tumor Prognostic Factors and the 1999 World Health Organization Second International Consultation on Prostate Cancer. Semin Urol Oncol 1999;17:222-272.

57 Lewis. Jr JS, Vollmer RT, Humphrey PA. Carcinoma extent in prostate needle biopsy tissue in the prediction of whole gland tumor volume in a screening population. Am J Clin Pathol 2002;118: 442-450.

58 Bismar TA, Lewis JS, Vollmer RT, et al. Multiple measures of carcinoma extent versus perineural invasion in prostate needle biopsy tissue in prediction of pathologic stage in a screening population. Am J Surg Pathol 2003;27:432-440.

59 Association of Directors of Anatomic Surgical Pathology. Recommendations for the reporting of resected prostate cancers. Am J Clin Pathol 1996;105: 667-670.

60 Ross JS, Sheehan CE, Dolem EM, et al. Morphologic and molecular prognostic markers in prostate cancer. Adv Anat Pathol 2002;9:115-128. 